\title{
Research on Traditional Villages Tourism Resources Analysis Based on GIS: \\ A Case Study on Zichuan District, Zibo City, Shandong Province, China
}

\author{
Simin $\mathrm{Ma}^{1}$, Xiuqing Fang ${ }^{2}$ \\ ${ }^{1}$ Ph. D. Course, Arts Management, Gachon University, Korea, anndamymoon@163.com \\ ${ }^{2}$ Adjunct Professor, Arts Management, Gachon University, Korea, bangsk@gachon.ac.kr
}

Corresponding author: Xiuqing Fang

\begin{abstract}
The traditional villages from various regions of China condense historical memories, and their unique nature and culture attract countless visitors. With the development of society, traditional villages gradually die out, thus it is urgent to protect and promote the development of traditional villages. This paper systematically analyzed the spatial pattern of traditional villages and the tourism resources in Zichuan District, Zibo City, Shandong Province, China using multi-source data such as network data, statistical data, GIS, and mathematical statistics analysis methods to find methods to protect and renew the traditional villages and develop tourism resources in the said district, and ultimately, contribute to the protection of the historical treasures of the Chinese nation. The results showed that: first, the traditional villages in Zichuan District appeared cluster distribution in space; second, the road connection degree in Zichuan District was common and the route was relatively single, which was the main factor restricting the development of traditional villages, and; third, traditional villages in Zichuan District should be integrated by sub-region and develop synergistically in the form of "small regions". This study can provide a scientific basis for the excavation and activation of traditional villages in Zichuan District and build a Shandong-style model for rural revitalization in Shandong Province, China.
\end{abstract}

Keywords: Traditional Villages, Zichuan District, Spatial Analysis, GIS, Regional Integration of Tourism Resources

\section{Introduction}

The development of social economy and the advancement of urbanization increased the town areas while decreasing the rural areas, putting rural villages in a backward and old state, the young labor force moving to urban cities, with much empty land and unused houses. Problems such as poor villages, low living standards, arbitrarily enclosing land, and destroying the natural environment greatly limit the development of rural villages[1].

As a form of a village, traditional villages possess plentiful culture and natural resources, rich historical information and cultural buildings, long-standing farming culture, beautiful natural landscape, and unique regional culture are unique treasures. Studying and developing the traditional villages are of great value to human beings. Protecting and developing the traditional villages are needed to ensure the diversity of Chinese traditional culture and to revitalize the strategy and

Received: August 05, 2020; $1^{\text {st }}$ Review Result: September 22, 2020; $2^{\text {nd }}$ Review Result: November 09, 2020 Accepted: December 28, 2020 
modernization of villages in China[2]. One of the important ways to develop traditional villages is to develop traditional village tourism. While protecting the ecological environment and protecting the local people's lives, we should develop local tourism and ecotourism, take the living environment and humanistic style of traditional villages as the characteristic tourism resources, attract foreign tourists to inject new vitality into them, and promote the industrial economy of traditional villages[3]. At the same time, the commercialization of traditional village culture can improve the enthusiasm of villagers to learn local culture, enhance the identity of villagers, and promote the "living state" inheritance of traditional villages.

The spatial distribution of traditional villages in China and the study of tourism mainly include two levels: national and provincial. The study of provincial scale mainly focuses on Yunnan, Guizhou, Shanxi, Hunan, Guangdong, Henan, Jiangxi, and other provinces with more traditional villages, less involved in Shandong. Zibo City, Shandong Province, China is a famous historical and cultural city with a long history. It is the birthplace of Qi culture and the origin of world football and a large number of historical traditional villages have been gathered here. Their development is also facing many problems and challenges. This paper takes the traditional villages in Zichuan District of Zibo City as the research object to analyze the tourism resources, which have certain value and significance for the protection, development and inheritance of history and culture of the traditional villages in Zichuan City. It also provides scientific basis for building Qilu model of traditional village protection.

Firstly, through consulting the relevant literature, this paper presented a comprehensive and meticulous understanding of GIS technology, Zichuan District, ecotourism, tourism resources, regional integration, etc. Through on-site survey and investigation of Zichuan District, the current situation of traditional villages can be understood, including natural ecological environment, traditional folk characteristic culture, etc., as well as Zichuan District, natural resources, characteristic buildings and their geographical location, and then the relevant picture and text data were recorded and summarized. The research ideas were determined, thus providing the theoretical data preparation for the research content. Secondly, in combination with the collected data and references, aiming at the distribution and types of tourism resources in traditional villages in Zichuan District, the study used the GIS software, qualitative and quantitative analysis method, nearest neighbor index analysis method, and connectivity analysis method to summarize and classify the spatial characteristics of tourism resources. At the same time, according to the collected data combined with the results of spatial analysis and the urban development planning of Zichuan District, the GIS software was adopted to integrate regional tourism resources. Reasonable tourism routes were designed, and tourism development suggestions were proposed, which should not only promote the economic development of traditional villages, but also not ignore the protection of the local natural environment and regional culture.

\section{Previous Research}

\subsection{Overview of Overseas Studies}

The study of traditional villages began earlier abroad. In the early 20th century, Europe and the United States began to study the cultural heritage of traditional villages, including historical buildings, cultural relics transition and historical and cultural towns, block protection and so on. In the 1980s, France had a serious imbalance in urban and rural development, the traditional villages' area became an uninhabited area. In order to solve this problem, France government proposed the Protection and Renaissance Plan for Traditional Villages and spent a lot of time on building rural infrastructure[4]. However, the protection on traditional villages in Britain got benefit from the praise and yearning by the early aristocrats and gentry on the natural scenery of the countryside, protected and built the 
countryside landscape. In 1932, the British government issued the Urban Planning Law[5], which first wrote rural planning into the law and raised the development and protection of rural law to the national level. Europe and the United States have rich experience in protecting and developing the traditional villages. They delimited protected areas, promulgated relevant laws, established many regions and international organizations, and gradually expanded the protection subject from national scholars to people individuals, providing ideas and methods for other regions and countries to develop and protect traditional villages. At present, with the progress and wide application of science and technology, GIS technology has been widely used in rural tourism. In 1991, Berry used GIS to plan a primitive island in the United States, which was the earliest case of GIS application in tourism planning[6]. Generally speaking, foreign research on traditional villages is earlier, rich in content, and the application of GIS methods is more advanced.

\subsection{Overview of Domestic Studies}

The research on traditional villages in China started late. Before 2012, the study area of traditional villages and ancient villages was not highly distinguished, and there is a small number of studies on traditional village tourism. There are three phases for the study of the integration of the protection and development of ancient villages in China: the years from 1990 to 1996 were regarded as the inception phase where the tourism value of the traditional villages was recognized but did not gain the attention; the years from 1997 to 2001 were regarded as the initial phase where the traditional villages had become the theme of tourism research but the research direction was few and the degree of research was uneven; the years from 2002 to present were regarded as the development phase where the ancient village tourism research has been comprehensively carried out and the literature has greatly increased. At present, the research mainly focuses on the minority areas in southwest China, such as Yang Xingyan, Zhao Cuiwei[7] and Liu Xingzhao[8], who studied the spatial distribution of traditional villages in Guizhou and Fujian Province and its influencing factors respectively. The research content is mainly on spatial distribution of traditional villages, such as Tian Hai[9] whose study was mainly on the spatial distribution of traditional villages in Beijing, Tianjin and Hebei. Zhang Hui[10] analyzed the spatial distribution of traditional villages in Taihang Mountain area. Studies based on purpose aspects mainly on beautiful rural construction and environmental restoration, include the study of Zhang Jing[11] on the protection and development of traditional villages under the background of beautiful rural construction. Xiang Yuanlin[12] studied the genetic variability of Shaanxi traditional village landscape based on precision restoration. In general, such small scale research taking the eastern coastal areas of China as the research object is less. This study takes Zichuan District of Zibo City, Shandong Province as the research object that can make up for this deficiency.

\section{Spatial Analysis on Tourism Resources}

\subsection{Spatial Analysis of Traditional Villages Tourism Resources in Zichuan District}

In Zichuan District, most of the tourism resources are distributed around the villages, and the spatial characteristics of the villages were analyzed by taking the villages as the research unit, reflecting the spatial characteristics of relics and cultural traditions around each village site.

\subsubsection{Qualitative Analysis}

Most of the villages in Zichuan District are mountainous and hilly areas, which are strongly affected by topographic conditions. The spatial differentiation of natural tourism resources and human tourism 
resources is remarkable. There are rich natural resources and many kinds of scenic spots. Folk customs, specialty products, celebrity sites, and scenic spots do have their own characteristics, and are distributed in the southeast of Zichuan District mostly. Qishan and Tanxi Mountain are the most representative ones. Qishan is located in Zichuan District, Zibo City, $5 \mathrm{~km}$ south of Taihe Town government, covering an area of 36 square kilometers, is the only national AAA level natural sightseeing scenic spot with the theme of Qi culture. There are more than 30 natural scenic spots in Qishan Scenic area, among which the most representative scenic spots are: Guanyin waterfall, Tang Sanzhai, ancient trestle, Qimen Cave, etc. Tan Xi Shan tourist area is located in King of the World's Short Stories - Pu Songling's hometown 38km southeast - Zichuan Taihe Town. It is 867 metres above sea level, the planned area there is 9 square kilometres, the vegetation in the scenic area is abundant, forest cover is over $80 \%$, it is a unique "natural oxygen bar". Tanxi Mountain belongs to the Lushan branch of Yimeng Mountain, the core area of the scenic area is 9 square kilometers and the scenic area is 86 square kilometers. Here are Over 10 peaks, the lowest elevation is 388 meters, and the highest is 820 meters. Under the mountain peak, the mountains are connected and crisscrossed. There are nine mountains in the whole scenic area, like a dragon falling from the sky, gathered under the mountain Jiulong Tan[13].

Zichuan District has a strong cultural atmosphere, which is represented by Liaozhai story and $\mathrm{Pu}$ Songling residence and concentrated in the northwest of Zichuan District. Liaozhai City is a scenic spot with the theme of Liaozhai Story. It is located in Pujiazhuang, Hongshan Town, Zichuan District, Zibo City. The park is divided into six parts: art exhibition hall, fox fairy garden, stone hidden garden, Liaozhai palace, Manjing temple and View Fox Garden. Pu Songling Memorial Hall which is in Liaozhai City tourist attraction completely preserved the original appearance of $\mathrm{Pu}$ Songling's residence. It is a typical northern rural courtyard. A Chinese culture glass creative garden is also here, which is the first project in China to display glass manufacturing as the theme. It covers a total area of $53 \mathrm{mu}$ with a total investment of 150million. It is a comprehensive creative park which showcases the research and development design, on-site production, exhibition and cultural tourism. This garden promotes the inheritance and protection of glass culture[14].

\subsubsection{Quantitative Analysis}

The nearest neighbor index was used to carry out the spatial analysis on each village, and the distance between the closest point and the point was used to describe its distribution[15].

(1) Calculate the distance from any point to its nearest neighbor $d_{\text {min }}$

(2) Calculate the average nearest neighbor distance of point-like things

$$
\overline{\mathrm{d}}_{\min }=\frac{1}{\mathrm{n}} \sum_{\mathrm{i}=1}^{\mathrm{n}} \mathrm{d}_{\text {min }}
$$

(3) Calculate nearest neighbor index

$$
R=2 \overline{\mathrm{d}}_{\min } \sqrt{\frac{n}{A}}
$$

$\mathrm{n}$ : the number of the point; A: region area; R: nearest neighbor index;

The resulting $\mathrm{R}$ values are compared in Fig. 1 to obtain the agglomeration and distribution status of regions.

Forty-eight traditional villages in Zichuan District were selected, the distance between each point and its nearest neighbor was calculated, $\overline{\mathrm{d}}_{\min }=2.52 \mathrm{~km}$ was obtained, the area of Zichuan district $\mathrm{A}=$ $960 \mathrm{~km}^{2}, \mathrm{n}=48$, and the nearest neighbor index $\mathrm{R}=1.08>1$ were obtained, indicating that the traditional villages' distribution in Zichuan District were an agglomeration. 


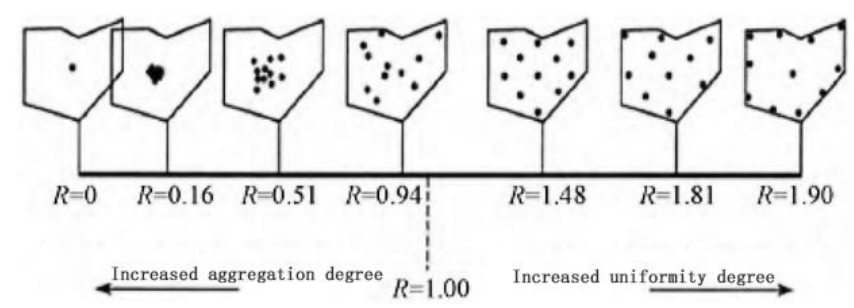

[Fig. 1] Distribution Mode of Nearest Neighbor Index

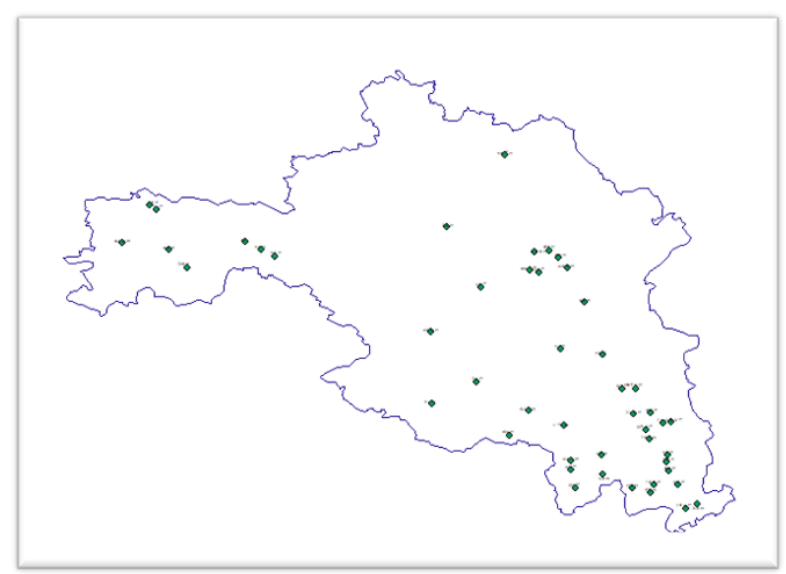

[Fig. 2] Select Village Distribution in Zichuan District

To sum up, due to topography and other factors, each traditional village and its resource distribution have a tendency of agglomeration, but the overall distribution is relatively scattered and concentrated in small areas, rich in species with their own characteristics.

\subsection{Spatial Analysis of Road in Zichuan District}

The traditional villages and road routes in Zichuan District were used to make Topological Structure, and $\alpha$ and $\beta$ indices were used for connectivity analysis, that is, the connection level and unblocking degree of the traffic network in this area were calculated[16].

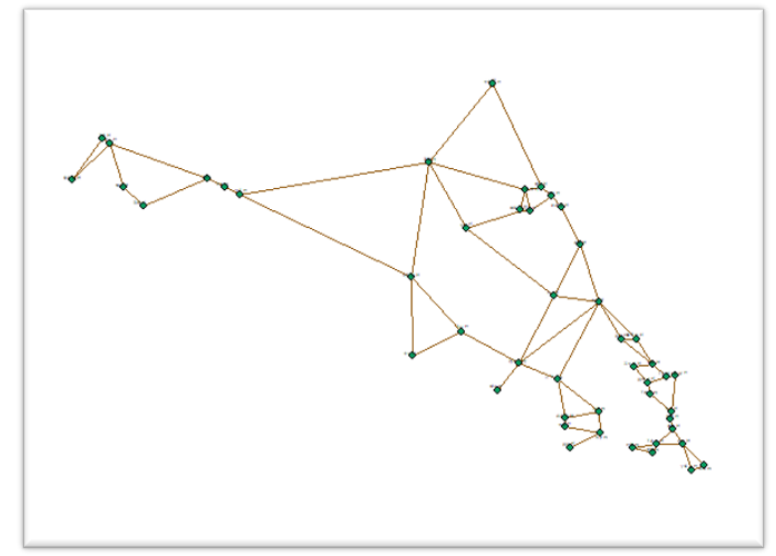

[Fig. 3] Topological Structure Diagram of Traditional Village and Traffic Route in Zichuan District

\subsection{1 $\alpha$ Index}

$\alpha$ Index is the degree to which the loops of existing nodes in a network exist.

$$
\alpha=\frac{L-V+1}{2 V-5}
$$


$\mathrm{L}$ : the number of actual connections in the network; V: the number of actual nodes in the network; $\alpha$ takes the number between 0 and 1 , when $\alpha$ equals 0 , it indicates that the network has no loop, when $\alpha$ equals 1 , it indicates that it has the maximum loop;

In Fig. 3, $\mathrm{L}=68$ and $\mathrm{V}=48$, so $\alpha=0.23$, the loop is poor, indicating that tourists may be required to visit the site as much as possible or all of the sites, and requiring a lot of original road returns.

\subsection{2 $\beta$ Index}

Index measures the degree of node connection

$$
\beta=\frac{L}{V}
$$

$\mathrm{L}$ : actual number of connections in the network; $\mathrm{V}$ : actual number of nodes in the network; $\beta$ index takes value between 0 and 3 , The bigger the $\beta$ index, the better the traffic connectivity;

In Fig. 3-3, $\mathrm{L}=68$ and $\mathrm{V}=48$, so $\beta=1.4$, the connectivity is fair.

In summary, due to the special terrain around the mountains and waters, the road network line is limited, resulting in a common degree of connection in the Zichuan District area, the route is relatively single. It would be time-consuming and labor-intensive for tourists to visit the whole area, but much more convenient if individual area was targeted.

Through the spatial analysis of tourism resources, the results show that: first, the traditional villages in Zichuan District appeared cluster distribution in space; second, the road connection degree in Zichuan District was common and the route was relatively single, which was the main factor restricting the development of traditional villages, and; third, traditional villages in Zichuan District should be integrated by sub-region and develop synergistically in the form of "small regions".

\section{Regional Integration and Development of Tourism Resources in Zichuan District}

\subsection{Regional Integration of Tourism Village in Zichuan District}

The area in Zichuan District is wide, there are many villages and towns, and the development progress of each village is different. The development of traditional villages is inseparable from the driving force of surrounding villages and towns. In order to design the integration area of tourism villages in Zichuan District, it is necessary to break up the traditional villages in Zichuan District into the part according to the spatial analysis and road analysis of tourism resources in Zichuan District, combined with the villages and towns development planning of each village and town, and relying on the drive of surrounding villages. At the same time, combining with the situation of surrounding villages and towns, it is also necessary to divide them into different regions for regional integration of tourism resources, which can effectively use the situation of traffic and village dispersion caused by mountains and rivers to form different tourism areas with regional characteristics, and thus promoting the economic development of each village[17].

There are three aspects of principle for regional integration of tourism villages in Zichuan District:

First, equal attention is paid to conservation and development. For the development of various resources, the ultimate purpose is to bring economic benefits, promote the development of social economy, without destroying the "foundation" of resources at the same time, so that resources can be used sustainably, especially the special resources bearing history and culture such as traditional villages and site relics and the natural formation landscape such as mountains and waters[18]. Once destroyed, it would be difficult to retrieve, and even affect the mankind, which requires us to pay attention to protecting their natural integrity and develop on its basis when developing and using village resources. 
Second, overall development and coordinated development. Zichuan District is a large entirety, which contains a variety of different tourism resources, and the development of tourism resources is different, including many famous scenic spots. These scenic spots have great impetus function, can drive the development of scattered villages around, so that the surrounding towns drive the development of villages, they can use the experience of one point to lead the whole area, so as to drive the development of the entire town in the form of region.

Third, highlight regional features. Tourist sites with distinctive characteristics can often attract tourists to visit[19]. Tourists visit not only the diversity of tourist resources in tourist sites, but also attach great importance to the characteristics of tourist sites. These characteristics are often impressive and forgettable. The integration of tourist villages is required to present these regional characteristics[20].

According to the above analysis and in combination with the overall planning of local villages and towns, the division and integration areas are shown in Table 1 below:

[Table 1] The expression of division and integration areas

\begin{tabular}{|c|l|}
\hline Name of Regions & \multicolumn{1}{c|}{ Introduction } \\
\hline Great Wall of Qi - Ma'anshan Historical \\
Culture Zone & $\begin{array}{l}\text { It is mainly located in the area of Zihe Area, Taihe Town. It is located along } \\
\text { the areas of Chengzi Village in Taihe Town, Pishan Mountain and } \\
\text { Ma'anshan. It is surrounded by the Great Wall of Qi. There are Ma'anshan, } \\
\text { the former site of the revolution during the Anti-Japanese War, Memorial } \\
\text { Hall, Martyrs' Garden, etc., as well as the Dawenkou Site Culture, the culture } \\
\text { formed by the flowing of Zihe River. }\end{array}$ \\
\hline $\begin{array}{c}\text { Qishan Mountain - Tanxi Mountain Natural } \\
\text { Scenic Spot }\end{array}$ & $\begin{array}{l}\text { It is mainly located in the Ezhuang Area of Taihe Town, surrounded by } \\
\text { mountains, with Qishan Mountain and Tanxi Mountain being the most } \\
\text { famous. The surrounding landscape has been developed mainly based on } \\
\text { Qishan Mountain and Tanxi Mountain to form a unique natural scenic area. }\end{array}$ \\
\hline $\begin{array}{c}\text { Sanglong Gorge - Ancient Porcelain Kiln } \\
\text { Satural Culture Complex Zone }\end{array}$ & $\begin{array}{l}\text { It includes Xihe Town, Longquan Town, and Zhaili Town. It is mainly } \\
\text { mountainous. There are Canglong Gorge, Xinglong Shihai Canyon, Juxiang } \\
\text { Mountain, and other natural landscapes, as well as Xipodi Kiln Site, Weiyi } \\
\text { Kiln Site, and other regional technological cultures, with many development } \\
\text { directions. }\end{array}$ \\
\hline Pu Songling - Lotus Nunnery Cultural Site \\
Zone & $\begin{array}{l}\text { It includes Hongshan Town and Luocun Town. The regional terrain is } \\
\text { relatively flat. There are Pujiazhuang homestay ancient complex, Lotus } \\
\text { Nunnery, Liaozhai City, and Pu Songling Former Residence. The region is } \\
\text { close to towns, thus, economic development and road traffic can effectively } \\
\text { promote the development of the region. }\end{array}$ \\
\hline Qingding Mountain - Niuji Nunnery & $\begin{array}{l}\text { It includes Lingzi Town and Kunlun Town. There are Qingyun Temple, } \\
\text { Qingding Mountain, Niuji Nunnery. The region is rich in natural resources, } \\
\text { economically developed, and the transportation is convenient. }\end{array}$ \\
\hline
\end{tabular}

\subsection{Suggestions on Regional Road of Tourism Villages Integration in Zichuan District}

The integration of Zichuan District is divided into five areas as shown in Fig. 4, 1)Qingding Mountain - Niuji Nunnery Natural Health and Leisure Zone, 2)Pu Songling - Lotus Nunnery Cultural Site Zone, 3)Canglong Gorge - Ancient Porcelain Kiln Site Natural Culture Complex Zone, 4)Qishan Mountain - Tanxi Mountain Natural Scenic Spot, and 5)Qi Changcheng - Great Wall of Qi Ma' anshan Historical Culture Zone. In each integration area, because of the special terrain surrounded by mountains, the internal roads of some areas are single, and the road connection degree is low, resulting in some areas requiring tourists to take a lot of repeated roads. This needs to plan the reasonable and necessary route according to the distribution of transportation routes in each region as well as the distribution of tourism resources and villages. The main roads between regions are obvious and convenient. According to the arrow in Fig. 4, it points to the movement between regions, where 
the cars are the main transportation vehicles. Inside each region, the main roads are predominant and the tourists are predominantly walking, in turn making sightseeing.

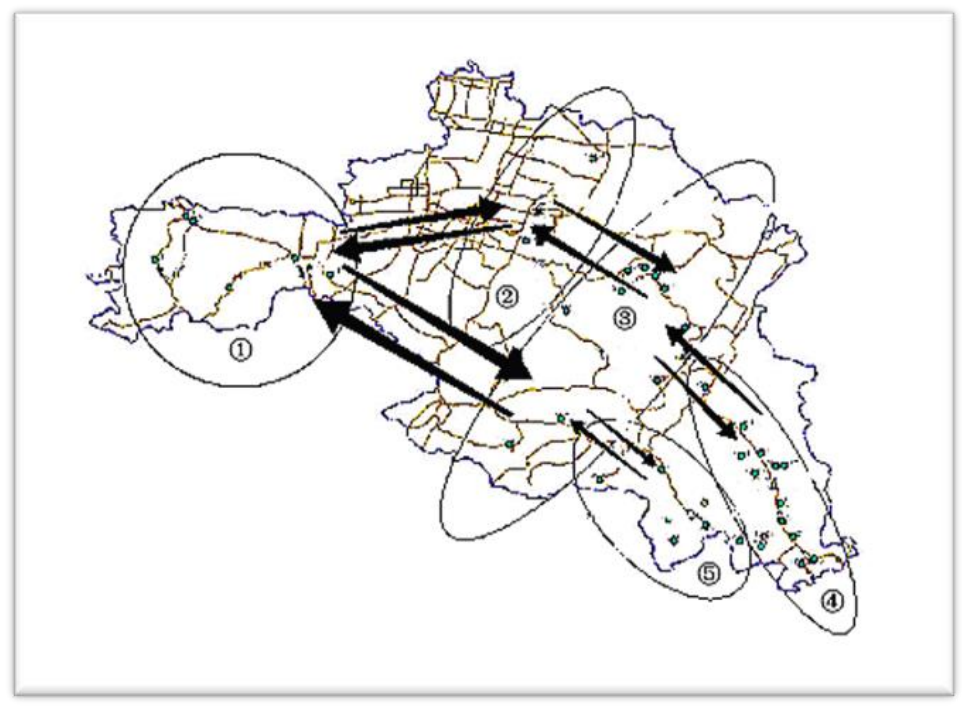

[Fig. 4] Regional Road Design of Tourism Village Integration in Zichuan District

Sample route instructions: take 1)Qingding Mountain - Niuji Nunnery Natural Health and Leisure Zone as the starting point, drive, take 510 provincial road, 231 provincial road to 3)Canglong Gorge Ancient Porcelain Kiln Site Natural Culture Complex Zone, it takes at least 40 minutes; from 3)Canglong Gorge - Ancient Porcelain Kiln Site Natural Culture Complex Zone (southern part), drive, take 006 county road, 007 county road to 5)Great Wall of Qi - Ma'anshan Historical Culture Zone, it takes at least 20 minutes; from 5)Great Wall of Qi - Ma'anshan Historical Culture Zone, drive, take Xingbo Road to the north, take Zizhong Road to 4)Qishan Mountain - Tanxi Mountain Natural Scenic Spot, it takes at least 30 minutes; from 4)Qishan Mountain - Tanxi Mountain Natural Scenic Spot, drive, take Zizhong Road, 006 County Road to 3)Canglong Gorge - Ancient Porcelain Kiln Site Natural Culture Complex Zone (northern part), it takes at least 30 minutes; from 3)Canglong Gorge Ancient Porcelain Kiln Site Natural Culture Complex Zone (northern part), drive, take Zizhong Road, Chongzheng Road to 2)Pu Songling - Lotus Nunnery Cultural Site Zone, it takes at least 20 minutes; from 2)Pu Songling - Lotus Nunnery Cultural Site Zone, drive, take Jiangjun East road, 205 National Highway to 1)Qingding Mountain - Niuji Nunnery Natural Health and Leisure Zone, it takes at least 30 minutes. Among them, tourism sites and travel routes can be freely selected and designed within each area.

\subsection{Suggestions on Tourism Village Development in Zichuan District}

Through the spatial analysis of tourism resources of traditional villages in Zichuan District and the analysis of regional integration and development of tourism resources, the following suggestions can be put forward for the development of tourism villages in Zichuan District:

First, there are so many villages in Zichuan District, and it is difficult for them to develop independently. They need the help and support of surrounding villages and towns to develop together in the form of small regions.

Second, the road connection degree is common. It is restricted by topographic factors, necessary to design a reasonable road network, build roads, enrich tourist movement routes, strengthen the connection degree of each tourist village, and repair damaged roads as required.

Third, actively achieve the collaboration among the government, villages and towns, villagers; mobilize the participation of the whole people; mobilize the enthusiasm of villagers to love the village; 
use their own hands to make the village richer; guide villagers; refer to successful cases; actively strive to learn, and; use each strength and resource scientifically and rationally.

Fourth, actively build characteristic tourism village, attract foreign talents, encourage talents to return to villages for construction; maintain site relics in a timely manner, and conduct the restoration of damaged resource in a sustainable manner.

Fifth, whether in the development process or when tourists visit, attention should be paid to the protection of the natural environment, to ensure the protection and protect in the development.

\section{Conclusions}

With the development of social economy and urbanization, the protection and development of Chinese traditional villages are restricted by many factors. It has become particularly important and urgent to promote the development of traditional villages.

In this paper, the traditional villages in Zichuan District, Zibo City, Shandong Province, China were taken as the research object. The GIS and mathematical statistics analysis methods were comprehensively used to spatially analyze the traditional village from both qualitative and quantitative aspects. In this regard, regional tourism resource integration and division were carried out. The results show that: first, the traditional villages in Zichuan District appeared cluster distribution in space; second, the road connection degree in Zichuan District was common and the route was relatively single, which was the main factor restricting the development of traditional villages, and; third, traditional villages in Zichuan District should be integrated by sub-region and develop synergistically in the form of "small regions". Thus, the traditional villages in Zichuan District should be integrated according to five regions: Great Wall of Qi - Ma'anshan Historical Culture Zone, Qishan Mountain Tanxi Mountain Natural Scenic Spot, Canglong Gorge - Ancient Porcelain Kiln Site Natural Culture Complex Zone, Pu Songling - Lotus Nunnery Cultural Site Zone, and Qingding Mountain - Niuji Nunnery Natural Health and Leisure Zone.

The suggestions for regional integration and development of traditional villages were put forward in this study, which provided a scientific basis for the excavation and activation of traditional villages in Zichuan District and develop a Shandong-style model for rural revitalization in Shandong Province, China.

Traditional villages are important tourism resources. This study has been systematically studied from qualitative and quantitative aspects, but there are still some limitations and shortcomings. First of all, from the point of view of the research object, the vague and incalculable resource analysis of cultural resources existing in each village is very few, under the influence of this special period, the data collection of specific tourism resources in the research area is limited, so the traditional results are slightly deficient. In addition, with the gradual development of the identification of traditional villages, the number of traditional villages is increasing year by year. The database of traditional villages should be further established to realize the dynamic analysis and research of traditional villages. Secondly, from the point of view of the research method, the application of GIS method in quantitative analysis is more prominent, but it is slightly insufficient for quantitative analysis. Although the quantitative analysis from the natural and humanistic aspects of the analysis, but the traditional village internal building characteristics, characteristics of customs and other follow-up research should be gradually strengthened. Finally, from the point of view of the research results, this study puts forward some suggestions on the tourism development of traditional villages in Zichuan District from the macro aspect, and the concrete implementation mechanism and implementation measures need to be further improved. 


\section{References}

[1] H. K. Yeo, Y. S. Cheon, The Study on Construct Dimension of City Image using Evaluation-type Affective Vocabulary, World Journal of Accounting, Finance and Engineering, (2018), Vol.2, No.1, pp.19-24.

[2] T. S. Park, A Study on the Direction of Mixed Research on Taekwondo and Tourism in Korea, International Journal of Art and Culture Technology, (2018), Vol.2, No.2, pp.1-6.

[3] D. H. Choi, Y. J. Seo, A Study on the Urban Regeneration Planning Elements for the Pedestrian-Friendly City Environment, International Journal of Art and Culture Technology, (2017), Vol.1, No.1, pp.9-14.

[4] W. Tong, Y. Bao, Study on the experience and reference of living protection of ancient village houses in France:To view how to avoid "hollowing heart" and retain "nostalgia" in Gaggio ancient village of Corsica, Modern Decoration (Theory), (2017), No.2, pp.149-150.

[5] J. J. Li, Core Concept and Realization Mechanism of Traditional Villages Conservation in Britain, Agricultural History of China, (2017), No.3, pp.115-124, 72.

[6] W. Yang, H. L. Liu, W. J. Zhao, GIS-based evaluation, analysis and planning of tourism resources in Yanqing, Science of Surveying and Mapping, (2010), No.3, pp.129-131, 128.

[7] X. Y. Yang, C. W. Zhao, Spatial Distribution and Influencing Factors of Residential Areas of Traditional Villages in Guizhou Province, Journal of Soil and Water Conservation, (2020), No.5, pp.389-395, 404

[8] X. Z. Liu, M. H. Xiao, Y. T. Xu, W. W. Xie, Analysis of Spatial relationship between traditional villages and Taobao Village in Fujian Province, Journal of Northwest Normal University (Natural Science Edition), (2020), No.5, pp.9098.

[9] H. Tian, Spatial Distribution Characteristics and Influencing Factors of Traditional Villages in Beijing, Tianjin and Hebei, Economic Geography, (2020), No.7, pp.143-149.

[10] H. Zhang, J. Q. Cai, S. Y. Xiao, J. J. Liu, X. C. Yue, Temporal and Spatial Distribution and Evolution Characteristics of Traditional Villages in Taihang Mountain Area, Urban Planning, (2020), pp.90-97.

[11] J. Zhang, Analysis of Traditional Village Protection and Development Strategy Under the Background of Beautiful Rural Construction, Urban Development Research, (2020), No.8, pp.37-43.

[12] Y. L. Xiang, M. M. Cao, J. Qin, C. Wu, Genetic Variability of Traditional Rural Settlement Landscape in Shanxi Based on Precision Restoration, Progress of Geographical Science, (2020), No.9, pp.1544-1556.

[13] S. Park, A Study on Rural Village Festival for Vitalization of 6th Industry, Asia-pacific Journal of Law, Politics and Administration, (2018), Vol.2, No.2, pp.1-6.

[14] B. S. Reddy, Data Structure in Miscillinious Environments, International Journal of IT-based Business Strategy and Management, (2017), Vol.3, No.1, pp.1-6.

[15] Y. N. Wu, D. H. Yang, Y. X. Wu, S. Y. Ji, Analysis of Main Tourism Resources in Hainan Province based on GIS Spatial Distribution Characteristics, Journal of Zhejiang Agricultural Sciences, (2017), No.5, pp.869-872.

[16] Y. W. Dai, Spatial Characteristic Analysis and Integration Development of Geological Tourism Resources in Western Hubei, Hubei University, Master's thesis, (2017)

[17] T. S. Park, Establishing a Theoretical System for Tae Kwon Do Tourism as Cultural Tourism, Asia-Pacific Journal of Advanced Research in Music, Art, Culture and Literature, (2016), Vol.1, No.1, pp.43-48.

[18] Y. J. Kim, H. S. Kim, Y. H. Kim, J. I. Choi, Estimation of Willingness to Pay for Virtual Reality Theme Park, International Journal of Business Policy and Strategy Management, (2017), Vol.4, No.1, pp.35-40.

[19] K. M. Bae, S. H. Lee, Y. S. Kim, Elements of TV Travel Shows Motivating Viewers to Travel: Focus on Korean TV Reality Shows, International Journal of IT-based Business Strategy and Management, (2018), Vol.4, No.1, pp.23-28.

[20] Y. S. Soo, Influence of Dutch Seventeenth-Century Landscape on the Caspar David Friedrich's Landscape, AsiaPacific Journal of Advanced Research in Music, Art, Culture and Literature, (2017), Vol.2, No.2, pp.1-6. 